\title{
Modification and co-option of leaf developmental programs for the acquisition of flat structures in monocots: unifacial leaves in Juncus and cladodes in Asparagus
}

\author{
Hokuto Nakayama ${ }^{1}$, Takahiro Yamaguchi ${ }^{2}$ and Hirokazu Tsukaya ${ }^{2}$ * \\ ' Department of Bioresource and Environmental Sciences, Faculty of Life Sciences, Kyoto Sangyo University, Kyoto, Japan \\ ${ }^{2}$ Department of Biological Sciences, Graduate School of Science, The University of Tokyo, Tokyo, Japan
}

\author{
Edited by: \\ Madelaine Elisabeth Bartlett, Brigham \\ Young University, USA \\ Reviewed by: \\ Minsung Kim, University of \\ Manchester, UK \\ Elizabeth Barker, University of \\ Calgary, Canada \\ *Correspondence: \\ Hirokazu Tsukaya, Department of \\ Biological Sciences, Graduate School \\ of Science, The University of Tokyo, \\ Science Building \#2, 7-3-1 Hongo, \\ Bunkyo-ku, Tokyo 113-0033, Japan \\ e-mail: tsukaya@biol.s.u-tokyo.ac.jp
}

It has been suggested that modification and co-option of existing gene regulatory networks (GRNs) play an important role in the morphological diversity. In plants, leaf development is one of active research areas, and the basic GRN for leaf development is beginning to be understood. Moreover, leaves show wide variation in their form, and some of this variation is thought to be the result of adaptation. Thus, leaves and leaf-like organs are an emerging and interesting model to reveal how existing GRNs give rise to novel forms and architectures during evolution. In this review, we highlight recent findings in evo-devo studies, especially on Juncus unifacial leaves, which are composed of lamina with abaxialized identities, and Asparagus cladodes, which are leaf-like organs at the axils of scale leaves. Based on these studies, we discuss how flat structures have evolved and morphologically diversified in shoot systems of monocot species, focusing on the modification and co-option of GRN for leaf development.

Keywords: Asparagus, cladode, evolution, gene regulatory networks, Juncus, leaf, leaf-like organ, unifacial leaf

\section{INTRODUCTION}

Plants display remarkable morphological diversities (Bell, 2008), which are largely a result of morphological variations of the shoot consisting of leaves, internodes, and axillary buds (flowers are considered as reproductive shoots consisted of modified leaves; von Goethe, 1790; Tsukaya, 1995; Honma and Goto, 2001). Recent studies have revealed the mechanisms underlying the morphological diversity of shoots (Garcês et al., 2007; Kimura et al., 2007). Importantly, many of these studies suggested that the modification and co-option of existing developmental gene regulatory networks (GRNs) play an important role in the development of novel forms and organs. For example, a study of MADS-box genes, which are transcription factors that specify floral organ identities, indicated that modification of GRN for floral organ identity has led to acquisition of unusual floral organs (Kramer et al., 2007). Likewise, studies of class I KNOTTED-LIKE HOMEOBOX (KNOX1) genes, which are required for initiation and maintenance of the shoot apical meristem (SAM), indicated that co-option and modification of GRN for the meristem development play a role in the morphological diversity of leaves (Hay and Tsiantis, 2006; Piazza et al., 2010). GRNs are considered connected components, which can be rewired and transplanted into new developmental contexts. Thus, elucidating how existing GRNs give rise to novel forms and architectures is important for understanding both morphological diversity and adaptation processes.

Here, we discuss the modification and co-option of GRN for the establishment of adaxial-abaxial ( $\mathrm{ad}-\mathrm{ab}$ ) polarity, using two examples: Juncus unifacial leaves, in which leaf blades have only the abaxial identity, and Asparagus cladodes, which are leaf-like organs in the axils (Yamaguchi et al., 2010; Nakayama et al., 2012a).
Based on these results, we discuss the importance of modification and co-option of GRN for the acquisition of flat structures in monocots.

\section{BASIC GRNS OF LEAF ORGANOGENESIS REGARDING LEAF INITIATION AND ESTABLISHMENT OF DORSIVENTRALITY}

The mechanisms underlying the morphological diversity of leaves remain poorly understood, whereas the basic mechanisms of leaf development are beginning to be characterized (Tsukaya, 2006; Koenig and Sinha, 2010; Moon and Hake, 2010; Horiguchi and Tsukaya, 2011; Tsukaya, 2013). Since leaf primordia develop from a group of undifferentiated cells on the flank of the SAM, initiation of leaf primordia requires a transition of cell fate from pluripotent to determinate. In Arabidopsis, KNOX1 genes are known to be the transcription factors that maintain meristem activity in shoots (Long et al., 1996). Therefore, the expression of KNOX1 genes is down-regulated at initiation sites of leaf primordia within the SAM (Long et al., 1996; Guo et al., 2008). This repression is partially mediated by a protein complex containing ASYMMETRIC LEAVES 1 (AS1), a MYB domain transcription factor, and ASYMMETRIC LEAVES 2 (AS2), a LOB domain protein (Xu etal., 2003; Ueno etal., 2007), and this interaction is known as the ASYMMETRIC LEAVES1/ROUGHSHEATH2/PHANTASTICA-KNOX (ARP-KN$O X)$ module.

After the initiation of leaf primordia marked by the repression of KNOX1, an ad-ab polarity is established within leaf primordia. Cell fates in the root meristem are determined mainly by a positional cue rather than cell lineage (van den Berg et al., 1995; Scheres, 2001), and the positional cue plays an important role in the establishment of ad-ab polarity in leaf primordia (Wardlaw, 
1949; Steeves and Sussex, 1989). Leaf primordia innately possess positional information against the SAM: the adaxial side is derived from cells adjacent to the SAM, while the abaxial side is derived from more distant cells (Kidner and Timmermans, 2010). Microsurgical experiments have demonstrated that communication between the SAM and leaf primordia is required for the establishment of ad-ab polarity, and suggested that the SAM may release signal molecules (Sussex, 1951; Reinhardt et al., 2005). Recently, it has been demonstrated that succinic semialdehyde or similar derivatives may be SAM signal molecules (Toyokura et al., 2011). Moreover, many studies using various model species have demonstrated that ad-ab polarity is established via mutually antagonistic interactions between adaxial and abaxial determinants (reviewed in Chitwood et al., 2007; Yamaguchi et al., 2012). For example, AS1 represses the abaxial determinant, ETTIN/AUXIN RESPONSE FACTOR3 (ETT/ARF3), as a complex with AS2 (Iwakawa et al., 2007). Moreover, type III HOMEODOMAIN-LEUCINE ZIPPER (HD-ZIP III) transcription factors, PHABULOSA (PHB), REVOLUTA (REV), and PHAVOLUTA (PHV), specify adaxial fate in leaf primordia (McConnell and Barton, 1998; McConnell et al., 2001; Emery et al., 2003). Meanwhile, transcription factors such as $A R F 3, A R F 4, Y A B B Y$, and KANADI (KAN) specify abaxial fate (Eshed et al., 2001; Kerstetter et al., 2001; Pekker et al., 2005; Sarojam et al., 2010). Additionally, two small RNAs play an important role in establishment of ad-ab polarity. miR166 cleaves mRNA of HD-ZIP III on the abaxial side of leaf primordia (Rhoades et al., 2002; Emery et al., 2003). On the other hand, tasiR-ARF, which is derived from non-coding TAS3 precursor transcripts, represses the expression of ARF3 and ARF4 on the adaxial side (Fahlgren et al., 2006; Hunter et al., 2006). Therefore, miR165/166 and tasiR-ARF also specify the abaxial and adaxial cell fate, respectively. According to the established ad-ab polarity, the leaf lamina expands along the medio-lateral axis because outgrowth of the leaf lamina is promoted at the juxtaposition between the adaxial and abaxial sides of leaf primordia (Waites and Hudson, 1995). During outgrowth, it is known that the establishment of the middle domain marked by expression of WUSCHEL-RELATED HOMEOBOX (WOX) genes is required (Nakata et al., 2012). WOX1 and PRESSED FLOWER (PRS), which are negatively regulated by KAN and positively regulated by FILAMENTOUS FLOWER, maintain the middle domain and subsequently induces outgrowth of leaf lamina (Nakata etal., 2012). However, the precise mechanisms of lamina outgrowth along the medio-lateral axis are not fully understood.

These studies suggest that the mechanism underlying establishment of ad-ab polarity in leaves is both mutually antagonistic and robust as a result of the presence of redundant networks. However, mutants of $p h b-1 d, p h v-1 d$, as 1 , and as 2 show drastic phenotypes, such as radially symmetrical, trumpet-shaped, or peltate leaves (Waites and Hudson, 1995; McConnell and Barton, 1998; Xu et al., 2003). This suggests that modification and/or co-option of GRN for the ad-ab patterning can be associated with variations in leaf morphology. Moreover, understanding the GRN raises a general issue of whether it is associated with acquisition of flat structures or leaf-like organs, which remains an important question in plant morphological diversity.

\section{MODIFICATION OF GRN FOR LEAF DEVELOPMENT: UNIFACIAL LEAVES}

Unlike bifacial leaves common in angiosperms, unifacial leaves are characterized by an abaxialized leaf blade (Kaplan, 1975; Figure 1A). Interestingly, unifacial leaves have evolved repeatedly in monocots (Rudall and Buzgo, 2002; Yamaguchi and Tsukaya, 2010). However, the developmental and evolutionary processes of unifacial leaves remain largely uncharacterized, although several morphological studies have been performed. Many blades of unifacial leaves are flat despite being abaxialized, while establishment of ad-ab polarity is indispensable for lateral outgrowth of bifacial leaf blades (Waites and Hudson, 1995). This indicates that the flat form of leaves evolved independently in bifacial and unifacial leaves, and flat leaf blades in unifacial leaves may be regulated by mechanisms that differ from those of bifacial leaves (Yamaguchi and Tsukaya, 2010). Thus, unifacial leaves can be used as a model to investigate the evolution of leaf morphology, focusing on modification of ad-ab polarity (Kaplan, 1975; Rudall and Buzgo, 2002; Yamaguchi and Tsukaya, 2010).

Recently, Yamaguchi et al. (2010) explored the molecular mechanisms underlying the development and evolution of unifacial leaves in the genus Juncus. Juncus prismatocarpus has flat unifacial leaves (Figures 1B,C). In addition to morphological analysis, expression analysis was performed to confirm ad-ab polarity of leaf blades of J. prismatocarpus. As a result, a HD-ZIP III homolog was expressed in the presumptive region of xylem in procambial strands, whereas an ARF3 homolog was expressed throughout the entire outer region of the leaf blade (Figure 1D). These results demonstrated that the leaf blade of unifacial leaves was abaxialized, as suggested by morphological observations. Additionally, the results suggested that modification of the GRN involved in establishment of ad-ab polarity in leaf may have resulted in abaxialized leaves in the genus Juncus. To our knowledge, this was the first case in which abaxialized leaves were confirmed by gene expressions of both adaxial and abaxial marker genes, excluding mutants of model species.

Moreover, the study using Juncus identified an alternative mechanism of leaf blade flattening without establishing ad-ab polarity by analyzing hybrids of a pair of closely related species; namely, J. prismatocarpus (with flattened unifacial leaves) and $J$. wallichianus (with cylindrical unifacial leaves). The results demonstrated that an ortholog of DROOPING LEAF (DL), a member of the CRABS CLAW/DL subfamily of YABBY genes, promotes flattening of blades of unifacial leaves in the genus Juncus (Yamaguchi et al., 2010; Figure 1E). The DL ortholog was strongly expressed in flattened unifacial leaves of J. prismatocarpus, whereas it was weakly expressed in cylindrical unifacial leaves of J. wallichianus. Genetic analysis using interspecific hybrids between the two species revealed that the DL locus from J. prismatocarpus flattens the unifacial leaf blade (Yamaguchi et al., 2010). An important function of $Y A B B Y$ genes is thought to be the promotion of directional cell proliferation in the lamina (Nakayama et al., 2010; Yamaguchi et al., 2012), in addition to the induction of leaf lamina-specific genetic programs and shut-down SAM programs (Sarojam et al., 2010). DL in Oryza sativa thickens the midrib by promoting cell proliferation toward the shoot apex (Yamaguchi et al., 2004). Similarly, the DL ortholog in unifacial leaves flattens 

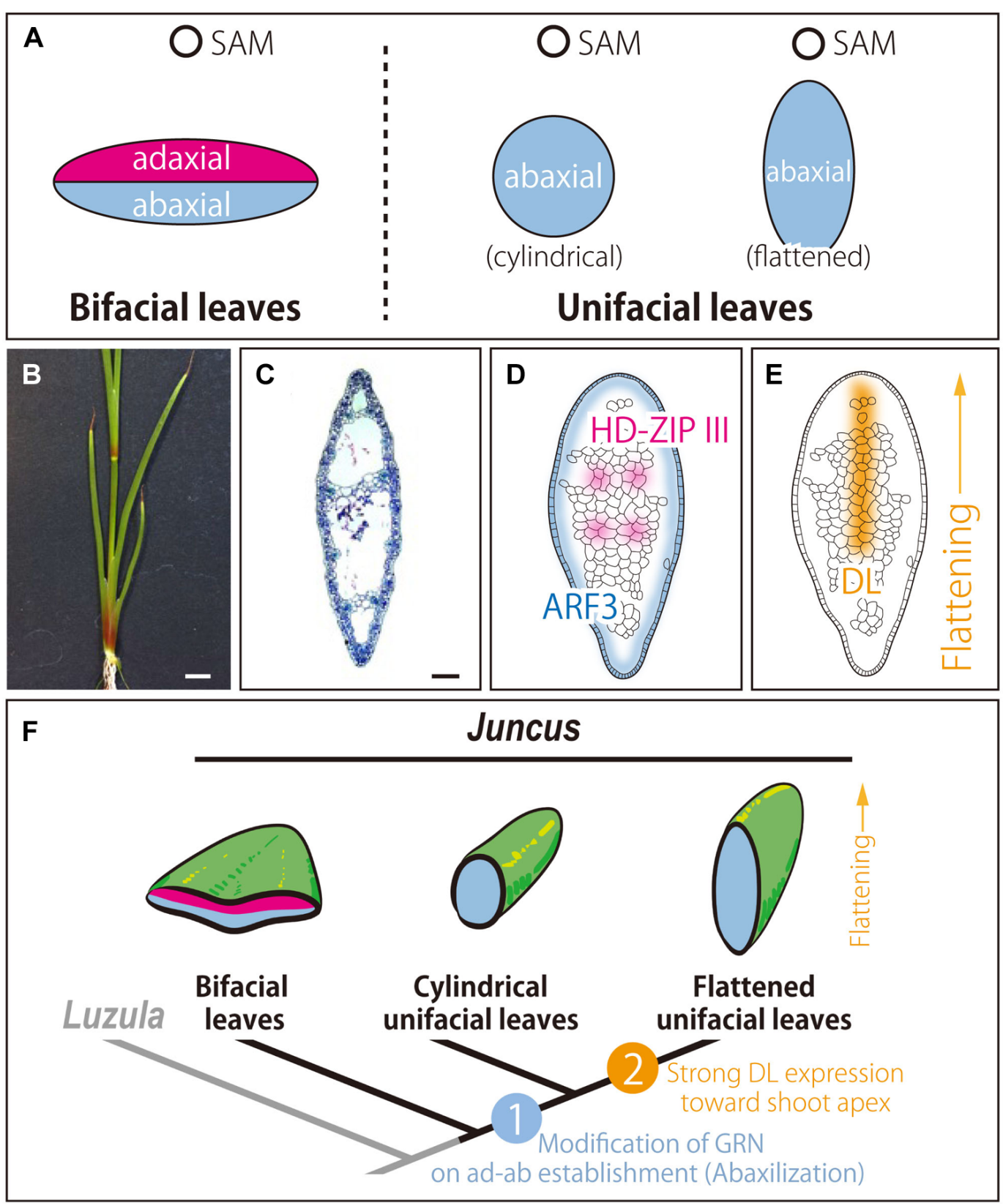

FIGURE 1 | Unifacial leaves in the genus Juncus. (A) Schematic diagrams of leaf polarities in bifacial and unifacial leaves. (B) Seedling. (C) Transverse section of the leaf blade. (D,E) Expression patterns of orthologs in leaf primordia. HD-ZIP III and ARF3 (D) and DL ortholog
(E). (F) Model of acquisition and blade flattening of unifacial leaves in the genus Juncus. (B-E) J. prismatocarpus. In (C-F), top of the image is the adaxial side. Bars $=1 \mathrm{~cm}$ in (B) and $200 \mu \mathrm{m}$ in (C). the abaxialized leaf blades by promoting cell proliferation toward the shoot apex. This flattening by the $D L$ ortholog may allow the leaf blades to stand straight to make the efficiency of light capture to be better.

These results suggested that modification of the GRN involved in the establishment of ad-ab polarity may have resulted in the evolution of unifacial leaves, and co-option of the GRN involved in directional cell proliferation may have resulted in the evolution of flattened unifacial leaves (Yamaguchi et al., 2010; Figure 1F).

\section{CO-OPTION OF GRN FOR LEAF DEVELOPMENT: CLADODES}

Foliage leaves in the genus Asparagus are reduced in size. Instead, Asparagus has unusual organs called cladodes in the axils of scale leaves (Figure 2A). Interestingly, the morphology of cladodes is leaf-like, although it develops in an axil where a lateral shoot generally arises (Figures 2A,B). Therefore, cladodes have received much attention from the morphological and evolutionary standpoints. However, the uniqueness of cladodes makes it difficult to understand their origin. Arber (1924) concluded that cladodes 

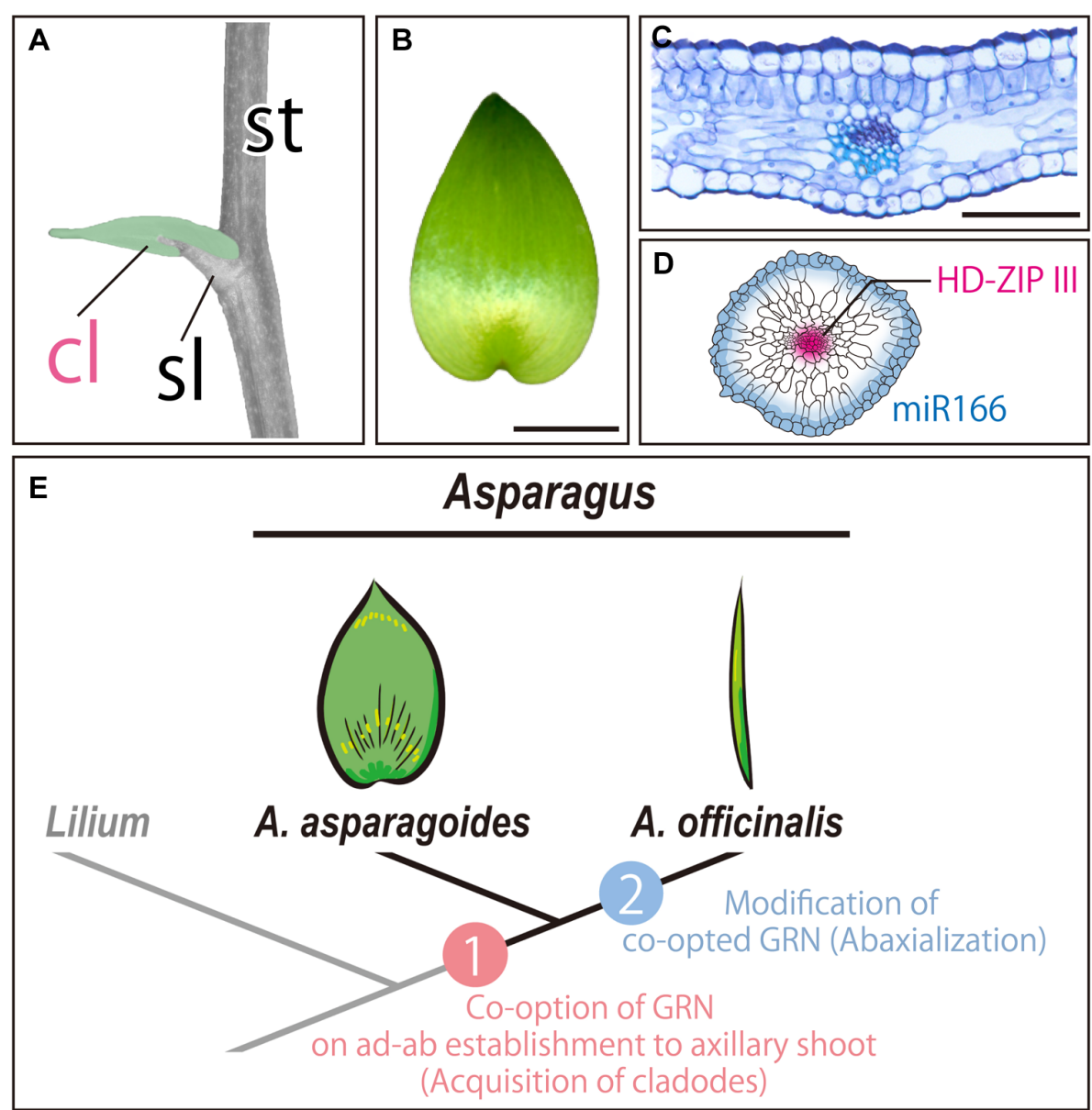

FIGURE 2 | Cladodes in the genus Asparagus. (A) Generating the cladode position. A cladode is indicated by a false-color (green). (B) Gross morphology of a leaf-like cladode. (C) Transverse section of a leaf-like cladode. (D) Expression pattern of HD-ZIP /II and miR166 in a rod-like (cylindrical) cladode. The image is a transverse section of a cladode. (E) Model of acquisition and morphological diversification of cladodes in the genus Asparagus. (A-C) A. asparagoides; (D) A. officinalis. cl, cladode; sl, scale leaf; st, stem. In (C-D), the top of the image is the adaxial side. Bars $=1 \mathrm{~cm}$ in $(\mathbf{B})$ and $1 \mathrm{~mm}$ in (C). are prophylls of abortive lateral shoots in the axils based on their leaf-like morphology and other anatomical features. Meanwhile, Cooney-Sovetts and Sattler (1986) and Kubitzki and Rudall (1998) concluded that cladodes are modified lateral branches based on their axillary position. Additionally, it is known that the morphology of cladodes in the genus is diverse (Kubitzki and Rudall, 1998; Fukuda et al., 2005). Recent molecular phylogenetic studies indicated that cladodes have evolved from a leaf-like (flattened) to a rod-like (cylindrical) form (Fukuda et al., 2005; Kubota et al., 2012). Currently, both the origin of and mechanisms underlying the diversification of cladodes remain unknown.

Nakayama et al. (2012a,b) investigated the molecular mechanisms underlying the acquisition and morphological divergence of cladodes in the genus Asparagus. Anatomical analysis demonstrated that leaf-like cladodes of $A$. asparagoides have ad-ab polarity (Figure 2C), and cell proliferation is concentrated in the proximal region. This suggested that the anatomy and development of cladodes are similar to those of leaves. However, the positions of the xylem and the phloem were inverted in cladodes compared to foliage leaves, suggesting that the cladodes differ from leaves (Nakayama et al., 2012a).

To further characterize the developmental processes of cladodes, expression analyses of orthologs of gene involved in leaf and/or shoot development were performed. The results showed that an ortholog of the KNOX1 gene was expressed in the cladode primordia. However, its expression was limited to the peripheral region of primordia and ultimately decreased. Indeed, an ortholog of AS1 was also expressed in the cladode primordia. Moreover, orthologous genes involved in the establishment of ad-ab polarity, such as $P H B, R E V$, and miR166, were expressed in a leaf-like manner (Nakayama et al., 2012a). Thus, cladodes are modified axillary shoots that have evolved by co-option of the GRN and establish ad-ab polarity in the axillary shoots, as well as confer the leaf-like planar form (Nakayama et al., 2012a,b).

This was supported by investigations of $A$. officinalis, which has cylindrical cladodes (Nakayama et al., 2012a). Anatomical features such as the inner morphology and distribution of stomata on the epidermis indicated that cladodes of A. officinalis are abaxialized. 
In agreement with these results, a $P H B$ ortholog was expressed in the presumptive region of vascular bundles, while miR166 was expressed throughout the outermost region of cladode primordia (Nakayama et al., 2012a; Figure 2D). Thus, the cylindrical form of the cladodes in A. officinalis can be attributed to the alteration of expression patterns of genes involved in the establishment of ad-ab polarity (Nakayama et al., 2012a). Molecular phylogenetic studies have suggested that the genus Asparagus has undergone rapid radiation in arid regions (Fukuda et al., 2005). The reduced surface area is thought to limit evapotranspiration and reduce water loss. Therefore, the morphological alteration from leaf-like to cylindrical forms likely contributed to the adaptation to arid and semiarid regions.

Overall, it was proposed that cladodes are modified axillary shoots, which have evolved by co-opting the GRN of leaf development. Subsequent alteration of the co-opted GRN has led to the cylindrical form of cladodes in the genus Asparagus (Nakayama et al., 2012a,b; Figure 2E). Therefore, the GRN of leaf development is likely required for the acquisition of leaf-like organs in the case of cladodes in the genus Asparagus.

\section{MODIFICATION AND CO-OPTION OF THE LEAF GRN IN PLANT MORPHOLOGICAL DIVERSITY}

In unifacial leaves and cladodes, modifications and co-option of existing GRNs have led to the flat form of cylindrical leaves and lateral shoots. However, the flattening processes differ between the two cases. In Asparagus cladodes, the GRN involved in leaf development is thought to be co-opted. Therefore, it seems likely that the regulation of flattening and subsequent lamina outgrowth in cladodes is similar to that in leaves: ad-ab polarity dependent lamina outgrowth. This was supported by analysis of cylindrical cladodes in A. officinalis (Nakayama et al., 2012a).

On the other hand, in unifacial leaves of Juncus, flattening and subsequent lamina outgrowth are regulated by a distinct mechanism. For flattening, the $D L$ ortholog promotes cell proliferation of abaxialized leaf primordia toward the SAM. Therefore, unlike bifacial leaves, flattening of primordia of unifacial leaves is independent of leaf ad-ab polarity. Additionally, the $D L$ and PRS expression patterns demonstrated that subsequent marginal outgrowth is also independent of ad-ab polarity and occurs along newly established central-marginal axes. Analysis of radial leaf mutants in J. prismatocarpus indicated that the rearrangement is induced by initial leaf flattening and is important to marginal outgrowth of unifacial leaves in Juncus (Yamaguchi et al., 2010). These suggested the existence of multiple mechanisms of flattening originally cylindrical structures.

Recently, Katayama et al. (2010) reported that flattened roots in Podostemaceae, which is a family of aquatic angiosperms, have evolved by co-option of genes involved in shoot development. Therefore, the mechanism of root flattening also should be explored for further understanding of acquisition processes of planar forms. In nature, many plants show flattened structures such as phyllodes, winged stems, and pterocaul stems. Additionally, many of these structures, unifacial leaves, and cladodes have evolved repeatedly during plant evolution. Therefore, studies of Juncus and Asparagus will increase our understanding of acquisition processes of these flattened structures.
Knowledge gained from evo-devo studies of Juncus unifacial leaves and Asparagus cladodes has an interesting similarity: modifications of GRNs have led to abaxialization of each organ. Such abaxialization has been observed in diversified plant forms (e.g., Kim et al., 2003; Toriba et al., 2010). Therefore, abaxialization may be a common way in which novel structures and morphology arise, regardless of organ type. As opposed to abaxialization, adaxialization has not been reported to result in morphological diversification, although it leads to cylindrical structures (McConnell et al., 2001). One possible reason is the original identity of the leaf primordia. It is known that establishment of ad-ab polarity in leaf primordia requires an adaxializing signal from the SAM, which may be mediated by GABA shunt metabolites (Sussex, 1951; Toyokura et al., 2011). Microsurgical experiments that separate a primordium from a meristem tip generate an abaxialized leaf, indicating that the original identity of leaf primordia is abaxial. Thus, it may be difficult to convert the identity of the whole leaf primordia into adaxial identity. Alternatively, some sort of morphological or physiological differences between adaxial and abaxial sides may be subjected to evolutionary constraints. In fact, it is known that the adaxialization was easily caused by a simple mutation in miR165/166 target sites of HD-ZIP genes (McConnell et al., 2001; Rhoades et al., 2002). Nevertheless, the adaxialized organs or forms have not been seen in nature. Therefore, the latter hypothesis may be worth considering. In any case, further analyses will reveal whether abaxialization is a general trend during evolution of plants and constraints of adaxialization and abaxialization.

In this review, we focused on the relation between morphological diversification and alteration of GRNs for leaf development taking Juncus and Asparagus as examples. These instances indicate that modification and co-option of existing GRNs are an effective way to give rise to novel forms and organs. Additionally, these instances shed light on the importance of abaxialization in morphological diversity. However, many questions in alteration processes of GRNs remain unanswered. One is how specific part of newly co-opted GRN is modified without any perturbation of other developmental processes. The other is why specific GRNs are co-opted repeatedly in various contexts of development during evolution. In addition to revealing function of individual genes, elucidation of these questions about evolution of GRN will allow us to better understand how novel forms or organs arise in nature.

\section{ACKNOWLEDGMENTS}

The authors thank all members of Tsukaya laboratory for discussion. This work was partially supported by the following sources: Grants-in-Aid for Scientific Research (A) to Hirokazu Tsukaya and for Creative Scientific Research to Hirokazu Tsukaya (18GS0313) from the Japan Society for the Promotion of Science, and for Scientific Research on Priority Areas to Hirokazu Tsukaya (19060002); a grant for Young Scientists (B) to Takahiro Yamaguchi (19770041) from the Ministry of Education, Culture, Sports, Science and Technology, Japan; a grant from the Mitsubishi Foundation to Hirokazu Tsukaya; the Sumitomo Foundation to Takahiro Yamaguchi; and a Research Fellowship from the Japan Society for the Promotion of Science to Hokuto Nakayama. 


\section{REFERENCES}

Arber, A. (1924). Myrisphyllum and Asparagus. Ann. Bot. 38, 635659. doi: $10.1111 / \mathrm{j} .1095-8339.1986$. tb01053.x

Bell, A. D. (2008). Plant Form: An Illustrated Guide to Flowering Plant Morphology. Portland: Timber Press. doi: 10.1242/dev.000497

Chitwood, D. H., Guo, M., Nogueira, F. T., and Timmermans, M. C. (2007). Establishing leaf polarity: the role of small RNAs and positional signals in the shoot apex. Development 134, 813-23. doi: 10.1111/j.10958339.1986.tb01053.x

Cooney-Sovetts, C., and Sattler, R. (1986). Phylloclade development in the Asparagaceae: an example of homeosis. Bot. J. Linn. Soc. 94, 327371. doi: 10.1016/j.cub.2003.09.035

Emery, J. F., Floyd, S. K., Alvarez, J., Eshed, Y., Hawker, N. P., Izhaki, A., et al. (2003). Radial patterning of Arabidopsis shoots by class III HDZIP and KANADI genes. Curr. Biol. 13, 1768-1774. doi: 10.1016/S09609822(01)00392-X

Eshed, Y., Baum, S. F., Perea, J. V., and Bowman, J. L. (2001). Establishment of polarity in lateral organs of plants. Curr. Biol. 11, 1251-1260. doi: 10.1016/j.cub.2006.03.065

Fahlgren, N., Montgomery, T. A., Howell, M. D., Allen, E., Dvorak, S. K., Alexander, A. L., et al. (2006). Regulation of AUXIN RESPONSE FACTOR3 by TAS3 ta-siRNA affects developmental timing and patterning in Arabidopsis. Curr. Biol. 16, 939-944. doi: 10.1111/j.1442-1984.2005.00131.x

Fukuda, T., Ashizawa, H., Suzuki, R., Nakamura, T., Ochiai, T. Kanno, A., et al. (2005). Molecular phylogeny of the genus Asparagus (Asparagaceae) inferred from plastid pet $B$ intron and petD-rpo $A$ intergenic spacer sequences. Plant Species Biol. 20, 121-132.

Garcês, H. M., Champagne, C. E., Townsley, B. T., Park, S., Malhó, R., Pedroso, M. C., et al. (2007). Evolution of asexual reproduction in leaves of the genus Kalanchoë. Proc. Natl. Acad. Sci. U.S.A. 104, 15578-15583. doi: $10.1105 /$ tpc.107.056127

Guo, M., Thomas, J., Collins, G., and Timmermans, M. C. (2008). Direct repression of KNOX loci by the ASYMMETRIC LEAVES1 complex of Arabidopsis. Plant Cell 20, 48-58. doi: 10.1038/ng1835

Hay, A., and Tsiantis, M. (2006). The genetic basis for differences in leaf form between Arabidopsis thaliana and its wild relative Cardamine hirsuta. Nat. Genet. 38, 942-427. doi: $10.1038 / 35054083$
Honma, T., and Goto, K. (2001). Complexes of MADS-box proteins are sufficient to convert leaves into floral organs. Nature 409, 525-529. doi: 10.3389/fpls.2011. 00024

Horiguchi, G., and Tsukaya, H. (2011). Organ size regulation on plants: insight from compensation. Front. Plant Sci. 2:24. doi: 10.3389/fpls.2011.00024

Hunter, C., Willmann, M. R., Wu, G., Yoshikawa, M., de la Luz Gutiérrez-Nava, M., and Poethig, S. R. (2006). Trans-acting siRNAmediated repression of ETTIN and ARF4 regulates heteroblasty in Arabidopsis. Development 133, 2973 2981. doi: 10.1111/j.1365-313X.2007. 03132.x

Iwakawa, H., Iwasaki, M., Kojima S., Ueno, Y., Soma, T., Tanaka, H., etal. (2007). Expression of the ASYMMETRIC LEAVES2 gene in the adaxial domain of Arabidopsis leaves represses cell proliferation in this domain and is critical for the development of properly expanded leaves. Plant J. 51, 173 184. doi: 10.1111/j.1365-313X.2007. 03132.x

Kaplan, D. R. (1975). Comparative developmental evaluation of the morphology of unifacial leaves in the monocotyledons. Bot. Jahrb. Syst. 95, 1-105. doi: 10.1105/tpc. 109.073189

Katayama, N., Koi, S., and Kato, M. (2010). Expression of SHOOT MERISTEMLESS, WUSCHEL, and ASYMMETRIC LEAVES1 homologs in the shoots of Podostemaceae: implications for the evolution of novel shoot organogenesis. Plant Cell 22, 2131-2140. doi: 10.1038/ 35079629

Kerstetter, R. A., Bollman, K., Taylor, R. A., Bomblies, K., and Poethig, R. S. (2001). KANADI regulates organ polarity in Arabidopsis. Nature 411, 706-709. doi: 10.1016/S00702153(10)91005-3

Kidner, C. A., and Timmermans, M. C. (2010). Signaling sides adaxialabaxial patterning in leaves. Curr. Top. Dev. Biol. 91, 141-168. doi: 10.1038 /nature01820

Kim, M., McCormick, S., Timmermans, M., and Sinha, N. (2003). The expression domain of PHANTASTICA determines leaflet placement in compound leaves. Nature 424, 438-443. doi: 10.1016/j.cub.2008. 04.008

Kimura, S., Koenig, D., Kang, J., Yoong, F. Y., and Sinha, N. (2007). Natural variation in leaf morphology results from mutation of a novel KNOX gene. Curr. Biol. 18, 672-677. doi: 10.1016/S0070-2153(10)91006-5

Koenig, D., and Sinha, N. (2010). Evolution of leaf shape: a pattern emerges. Curr. Top. Dev. Biol. 91, 169-183. doi: 10.1105/tpc.107.050385

Kramer, E. M., Holappa, L., Gould, B. Jaramillo, M. A., Setnikov, D., and Santiago, P. M. (2007). Elaboration of $B$ gene function to include the identity of novel floral organs in the lower eudicot Aquilegia. Plant Cell 19, 750 766. doi: 10.1105/tpc. 107.050385

Kubitzki, K., and Rudall, P. J. (1998). "Asparagaceae," in The Families and Genera of Vascular Plants, ed. K. Kubituki (Berlin: Springer-Verlag), 125-128. doi: 10.1007/s00122-0111709-2

Kubota, S., Konno, I., and Kanno, A. (2012). Molecular phylogeny of the genus Asparagus (Asparagaceae) explains interspecific crossability between the garden asparagus (A. officinalis) and other Asparagus species. Theor. Appl. Genet. 124, 345-354. doi: 10.1038/379066a0

Long, J. A., Moan, E. I., Medford, J. I., and Barton, M. K. (1996). A member of the KNOTTED class of homeodomain proteins encoded by the STM gene of Arabidopsis. Nature 379, 66-69. doi: 10.1038/379066a0

McConnell, J. R., and Barton, M. K. (1998). Leaf polarity and meristem formation in Arabidopsis. Development 125, 2935-2942. doi: $10.1038 / 35079635$

McConnell, J. R., Emery, J., Eshed, Y., Bao, N., Bowman, J., and Barton, M. K. (2001). Role of $P H A B$ ULOSA and PHAVOLUTA in determining radial patterning in shoots. Nature 411, 709-713. doi: 10.1016 j.pbi.2010.08.012

Moon, J., and Hake, S. (2010). How a leaf gets its shape. Curr. Opin. Plant Biol. 14, 24-30. doi: 10.1105/tpc.111.092858

Nakata, M., Matsumoto, N., Tsugeki, R., Rikirsch, E., Laux, T., and Okada, K. (2012). Roles of the middle domain-specific WUSCHELRELATED HOMEOBOX genes in early development of leaves in Arabidopsis. Plant Cell 24, 519-535. doi: 10.3732/ajb.0900378

Nakayama, H., Yamaguchi, T., and Tsukaya, H. (2010). Expression patterns of $A a D L$, a CRABS CLAW ortholog in Asparagus asparagoides (Asparagaceae), demonstrate a stepwise evolution of $C R C / D L$ subfamily of YABBY genes. Am. J. Bot. 97, 591600. doi: 10.1105/tpc.111.092924

Nakayama, H., Yamaguchi, T., and Tsukaya, H. (2012a). Acquisition and diversification of cladodes: leaf-like organs in the genus Asparagus. Plant Cell 24, 929-940. doi: 10.4161/psb.20913

Nakayama, H., Yamaguchi, T., and Tsukaya, H. (2012b). Cladodes, leaflike organs in Asparagus, show the significance of co-option of pre-existing genetic regulatory circuit for morphological diversity of plants. Plant Signal. Behav. 7, 961-964. doi: 10.1105/tpc.105.034876

Pekker, I., Alvarez, J. P., and Eshed, Y. (2005). Auxin response factors mediate Arabidopsis organ asymmetry via modulation of KANADI activity. Plant Cell 17, 2899-2910. doi: 10.1016/j.cub.2010.11.037

Piazza, P., Bailey, C. D., Cartolano, M., Krieger, J., Cao, J., Ossowski, S., et al. (2010). Arabidopsis thaliana leaf form evolved via loss of KNOX expression in leaves in association with a selective sweep. Curr. Biol. 20, 2223-2228. doi: 10.1242/dev.01544

Reinhardt, D., Frenz, M., Mandel, T., and Kuhlemeier, C. (2005). Microsurgical and laser ablation analysis of leaf positioning and dorsoventral patterning in tomato. Development 132, 15-26. doi: 10.1016/S00928674(02)00863-2

Rhoades, M. W., Reinhart, B. J., Lim, L. P., Burge, C. B., Bartel, B., and Bartel, D. P. (2002). Prediction of plant microRNA targets. Cell 110, 513-520. doi: 10.1201/9781420024982.ch23

Rudall, P. J., and Buzgo, M. (2002). "Evolutionary history of the monocot leaf," in Developmental Genetics and Plant Evolution, eds Q. C. B. Cronk, R. M. Bateman, and J. A. Hawkins (London: Taylor \& Francis), 431-458. doi: 10.1105/tpc. 110.075853

Sarojam, R., Sappl, P. G., Goldshmidt, A., Efroni, I., Floyd, S. K., Eshed, Y., et al. (2010). Differentiating Arabidopsis shoots from leaves by combined YABBY activities. Plant Cell 22, 2113-2130. doi: 10.1104/pp.125.1.112

Scheres, B. (2001). Plant cell identity. The role of position and lineage. Plant Physiol. 125, 112-114. doi: 10.1017/CBO9780511626227

Steeves, T. A., and Sussex, I. M. (1989). Patterns in Plant Development. New York: Cambridge University Press. doi: 10.1038/167651a0

Sussex, I. M. (1951). Experiments on the cause of dorsiventrality in leaves. Nature 167, 651-652. doi: 10.1105/tpc.110.075291

Toriba, T., Suzaki, T., Yamaguchi, T., Ohmori, Y., Tsukaya, H., and Hirano, H. Y. (2010). Distinct regulation of adaxial-abaxial polarity in anther patterning in rice. Plant Cell 22, 1452-1462. doi: 10.1093/pcp/pcr079 
Toyokura, K., Watanabe, K., Oiwaka, A., Kusano, M., Tameshige, T., Tatematsu, K., et al. (2011). Succinic semialdehyde dehydrogenase is involved in the robust patterning of Arabidopsis leaves along the adaxial-abaxial axis. Plant Cell Physiol. 52, 13401353. doi: 10.1093/pcp/pcr079

Tsukaya, H. (1995). "The genetic control of morphogenesis in Arabidopsis and its relevance to the development of biodiversity," in Biodiversity and Evolution, eds R. Arai, M. Kato, and Y. Doi (Tokyo: The National Science Museum Foundation), 253-265. doi: $10.1093 / \mathrm{pcp} / \mathrm{pcf051}$

Tsukaya, H. (2006). Mechanism of leaf-shape determination. Аnnu. Rev. Plant Biol. 57, 477-496. doi: 10.1146/annurev.arplant.57.032905. 105320

Tsukaya, H. (2013). "Leaf development," in The Arabidopsis Book, ed. K. Torii (Rockville: American Society of Plant Biologists). doi: 10.1199/tab.0163 elocation-id: e0163 (published online e0163).

Ueno, Y., Ishikawa, T., Watanabe, K., Terakura, S., Iwakawa, H., Okada,
K., et al. (2007). Histone deacetylases and ASYMMETRIC LEAVES2 are involved in the establishment of polarity in leaves of Arabidopsis. Plant Cell 19, 445-457. doi: 10.1038/378062a0

van den Berg, C., Willemsen, V., Hage, W., Weisbeek, P., and Scheres, B. (1995). Cell fate in the Arabidopsis root meristem determined by directional signalling. Nature 378, 62-65. doi: 10.1038/378062a0

von Goethe, J. W. (1790). Versuch die Metamorphose der Pflanzen zu erklären. Gotha: C. W. Ettinger.

Waites, R., and Hudson, A. (1995). phantastica: a gene required for dorsoventrality of leaves in Antirrhinum majus. Development 121 2143-2154. doi: 10.1105/tpc.060510

Wardlaw, C. W. (1949). Experiments on organogenesis in ferns. Growth 9, 93-131. doi: 10.1242/dev.00622

Xu, L., Xu, Y., Dong, A., Sun, Y., Pi, L., Xu, Y., etal. (2003). Novel asl and as 2 defects in leaf adaxial-abaxial polarity reveal the requirement for ASYMMETRIC LEAVES1 and 2 and ERECTA functions in specifying leaf adaxial identity. Development 130, 4097-4107. doi: 10.1105/tpc.018044

Yamaguchi, T., Nagasawa, N., Kawasaki, S., Matsuoka, M., Nagato, Y. and Hirano, H. Y. (2004). The YABBY gene DROOPING LEAF regulates carpel specification and midrib development in Oryza sativa. Plant Cell 16, 500-509. doi: 10.1093/ pcp/pcs074

Yamaguchi, T., Nukazuka, A., and Tsukaya, H. (2012). Leaf adaxialabaxial polarity specification and lamina outgrowth: evolution and development. Plant Cell Physiol. 53, 1180-1194. doi: 10.1007/s10265009-0255-3

Yamaguchi, T., and Tsukaya, $\mathrm{H}$ (2010). Evolutionary and developmental studies of unifacial leaves in monocots: Juncus as a model system. J. Plant Res. 123, 35-41. doi: 10.1105/tpc.110.076927

Yamaguchi, T., Yano, S., and Tsukaya, H. (2010). Genetic framework for flattened leaf blade formation in unifacial leaves of Juncus prismatocarpus. Plant Cell 22, 2141-2155. doi: 10.1105/tpc.110.076927
Conflict of Interest Statement: The authors declare that the research was conducted in the absence of any commercial or financial relationships that could be construed as a potential conflict of interest.

Received: 30 April 2013; accepted: 19 June 2013; published online: 09 July 2013. Citation: Nakayama H, Yamaguchi T and Tsukaya H (2013) Modification and cooption of leaf developmental programs for the acquisition of flat structures in monocots: unifacial leaves in Juncus and cladodes in Asparagus. Front. Plant Sci. 4:248. doi: 10.3389/fpls.2013.00248

This article was submitted to Frontiers in Plant Evolution and Development, a specialty of Frontiers in Plant Science. Copyright (C) 2013 Nakayama, Yamaguchi and Tsukaya. This is an openaccess article distributed under the terms of the Creative Commons Attribution License, which permits use, distribution and reproduction in other forums, provided the original authors and source are credited and subject to any copyright notices concerning any third-party graphics etc. 